\title{
Introduction to Subduction Zones
}

\author{
LARRY J. RUFF ${ }^{1}$ and HiRoO KANAMORI ${ }^{2}$
}

Subduction zones present many facades to those that observe them. From obvious features to obscure yet important processes, there are many aspects of subduction zones to observe and explain. Notable examples of obvious features are volcanoes, earthquakes, mountain belts, and deep sea trenches; while on the other hand, the unseen process of sediment subduction can produce long-term effects on the Earth's geochemical reservoirs. Indeed, most disciplines of the earth sciences have reasons to study subduction zones, and consequently all disciplines can make contributions to our understanding of subduction zones.

Each discipline has its own view of the subduction process. To volcanologists, subduction zones are the sites of volcanoes. The active volcanic belt is a ubiquitous feature of subduction zones; volcanoes may be built on continental or oceanic lithosphere. In addition, volcanism is associated with back-arc spreading. There is a considerable range in the composition of volcanic products in subduction zones. Many subduction zone volcanoes also represent great hazards to local populations, and violent eruptions may even cause global-scale variations in the atmosphere. To seismologists, subduction zones generate earthquakes, and are the most important tectonic setting for seismicity (see Figure 1). To geologists, subduction zones produce quite a diversity of geologic terranes and rock deformation, the settings vary from accretionary prisms to back-arc thrust regimes. To geodicists, subduction zones are the sites of some of the largest deviations in the gravity field as well as regions of dramatic horizontal strain and vertical uplift and subsidence.

But to plate tectonicists, subduction zones are relatively simple: subduction zones are convergent plate boundaries where oceanic lithosphere is consumed (see Figure 2). To embellish this "definition" from the perspective of global dynamics: subduction zones are regions where the cold upper thermal boundary layer of the convecting Earth sinks back into the hot mantle. The above definitions would seem to explain both the kinematic and dynamic role of subduction zones. But do these definitions explain why subduction zones are located where they are? what the

\footnotetext{
1 Dept. of Geological Sciences, University of Michigan, Ann Arbor, MI 48109 U.S.A.

2 Seismological Laboratory, California Institute of Technology, Pasadena, CA 91125 U.S.A.
} 


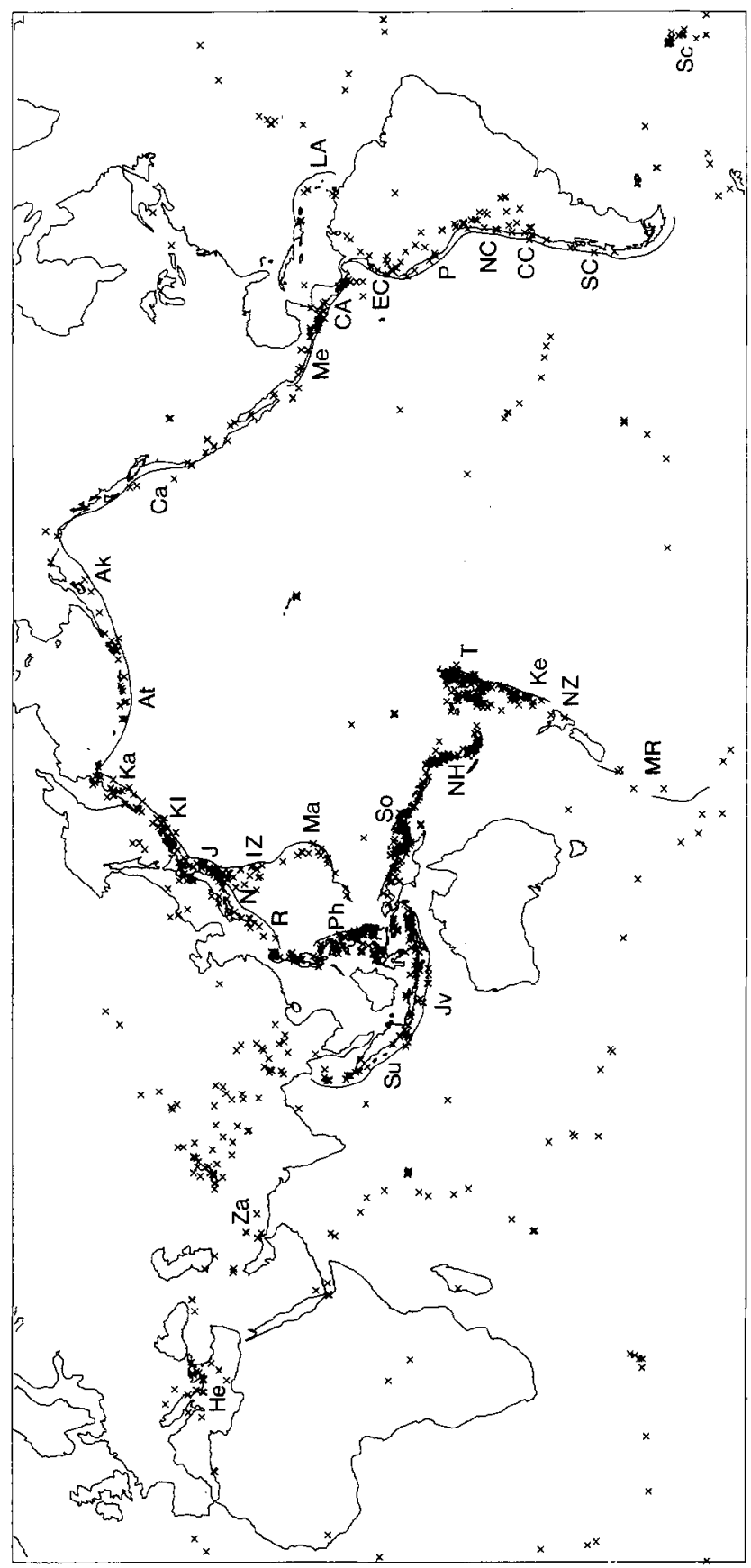

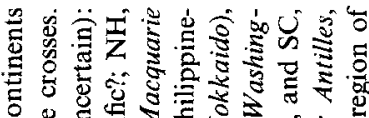

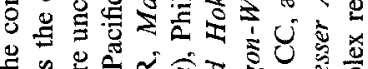

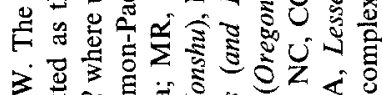

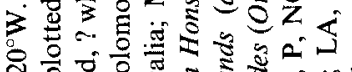

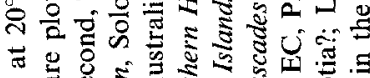

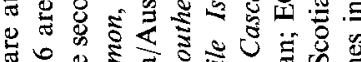

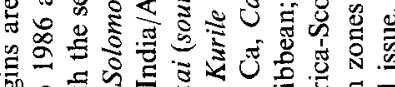

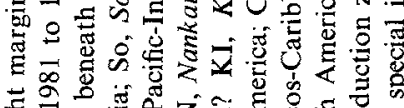

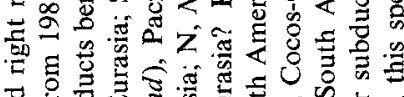

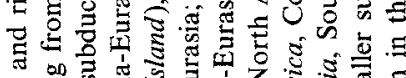

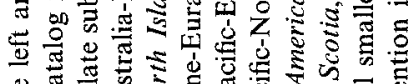

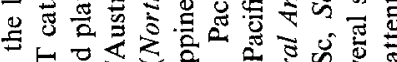

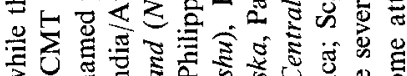
3 品

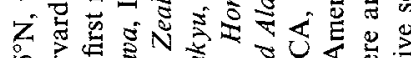

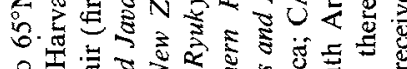

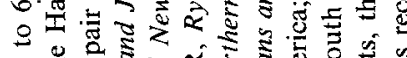

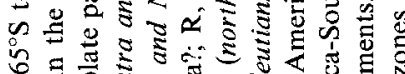

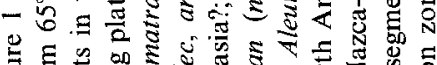

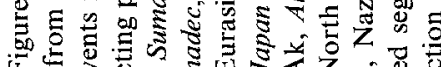

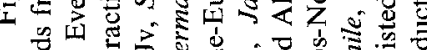

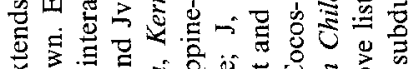
ช。

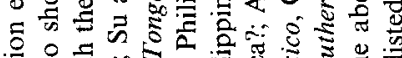

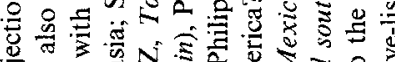

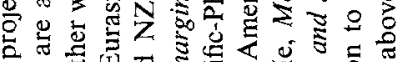

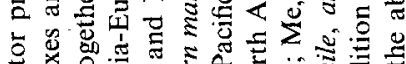
可

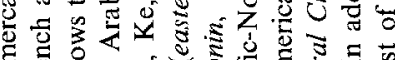

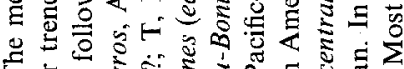

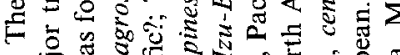

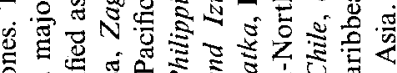

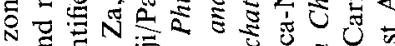
ธ。

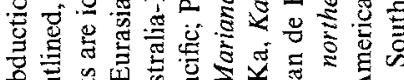

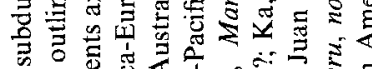

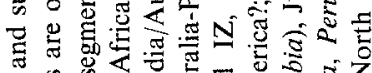

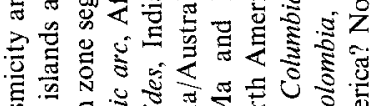

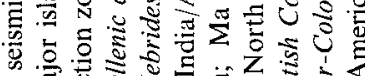

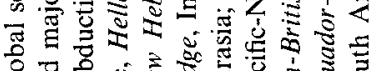

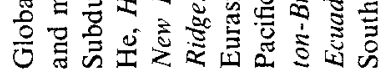


geometry of subduction zone segments will be? the physiography of island arcs? the generation of island arc volcanoes? back-arc spreading? the diversity of earthquake occurrence? style of accretionary prisms?--clearly not. While plate tectonics provides the underlying kinematic role of subduction zones, it does not explain the great variety of phenomena associated with subduction zones. Although earthquakes, volcanoes, trenches, and global recycling might be second-order phenomena within the plate tectonics scenario, they are still first-order problems within earth sciences. Researchers in their various fields must go beyond plate tectonics and global dynamics to make progress in explaining the great diversity of phenomena associated with subduction zones.

The diverse contributions in this special issue reflect the many facades of subduction zones. The style of the contributions also varies from review papers to speculative accounts of obscure processes. The special issue is divided into two volumes with a total of four different sections: in Volume I (1) global-scale reviews, (2) accretionary prism processes, and in Volume II, (3) tectonics and subduction initiation, and (4) earthquake occurrence. While the size of this special issue requires the division into two volumes, there is considerable linkage between the two parts. Indeed, several papers could appear in more than one section. In the global-scale review section of Volume I: Cloos and SHREVE present a two-part comprehensive description of accretionary prism and their model which explains several features; VASSILIOU and HAGER treat the problem of Wadati-Benioff zone seismicity and slab penetration with extensive modeling of stress regimes; WORTEL and VLAAR also treat Wadati-Benioff zone seismicity from the perspective of pressure-temperature controls on seismic/aseismic behavior; Hsur reviews some of the contributions of fluid mechanics to various processes associated with subduction zones; and MCLENNAN discusses the role of subduction zones in global geochemical cycling. Taken together, these global-scale discussions clearly indicate that many important present-day characteristics of subduction need to be better understood, not to mention the properties of subduction zones through time. In the accretionary prism processes section of Volume I: BRAY and KARIG examine the physical processes occurring in accretionary prisms, they focus on the dewatering process; SHI and WANG also present physical models of the accretionary prism with emphasis on heat flow; then COCHRANE et al. show the results of seismic experiments along the Cascades subduction zone to identify the deformational styles. Volume II is more focused on large-scale tectonics and/or seismicity. In the tectonics and subduction initiation section: CLOETINGH et al. treat the question of passive margin vulnerability to subduction initiation; SENO and TAKANO look at the remarkably complex triple junction interaction in central Honshu; MCCANN and HABERMANN present a model for the influence of ocean floor topography on segmentation of island arc platforms; while RUFF et al. present a seismotectonic study of the Macquarie Ridge complex and discuss the nature of subduction initiation. In the earthquake occurrence section of Volume II: HEATON and 


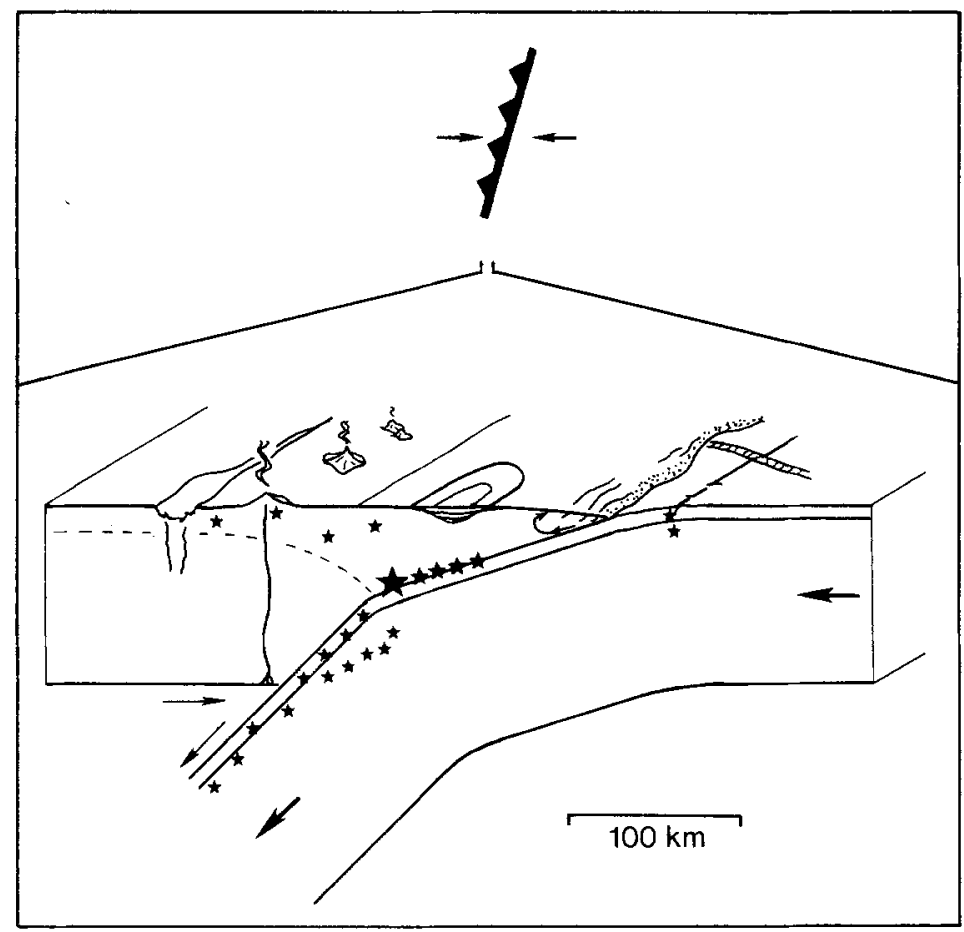

Figure 2

Two views of subduction zones. The map view at top depicts the role of subduction zones in plate tectonics; they are convergent plate boundaries where oceanic lithosphere is consumed. Upon closer examination (bottom), subduction zones display many features and processes of interest to many branches of earth science. Several of the important shallow features of subduction zones are represented in the cross-section: the oceanic lithosphere deforms as it subducts with normal faulting in the outer-rise and downward kinks at the trench axis and at a depth of $\approx 40 \mathrm{~km}$; seismicity is represented by the stars; large underthrusting earthquakes (large star) occur on the plate contact interface, but only in a certain depth range that extends down to about $40 \mathrm{~km}$; below this depth, seismicity occurs within the downgoing oceanic crust and upper mantle which also experience phase changes; "double Benioff zones" have been observed in the intermediate depth range; the deepest extent of the WadatiBenioff zone varies from a hundred to seven hundred kilometers; there is also scattered seismicity in the outer-rise and in the upper plate above the "critical" isotherm (dashed line); the accretionary prism is a dynamic system between the trench axis and coastline with faulting, material flow, sediment subduction, underplating, and basin formation; dewatering and sediment metamorphism also occur in this environment; a volcanic belt occurs above the apex of the corner flow where the asthenosphere beneath the upper plate is viscously coupled to the downgoing plate; back-arc spreading occurs behind the volcanic arc. The cross-section is highly stylized-not all subduction zones display these features. An essential characteristic of subduction zones is their variability, thus it is important to add the third dimension to the stylized subduction zone. All of the above discussed features vary along arc strike, and furthermore, subduction zones evolve with time. Most of the above mentioned characteristics and processes are addressed in this special issue. 
HARTZELl give a detailed assessment of the anticipated strong motions from a hypothetical future great earthquake along the Cascades subduction zone; SMITH et al. present a comprehensive geophysical study of the North Island (New Zealand) subduction complex and earthquake occurrence; MORIYAMA et al. propose that a zone of unusual seismic coupling exists in the Izu-Bonin arc; and RUFF presents a "comparative subductology" approach to the speculative connection between sediment subduction and great earthquake occurrence.

It is worth repeating that the diversity of contributions in this special issue reflects the diversity of interesting and unexplained aspects of subduction. Of the many facades that subduction zones present to us, the kinematic role in plate tectonics is the best understood aspect. Many of the primary geological, geochemical, and geophysical characteristics of subduction zones still require explanation. It is our hope that this issue will help spark further scientific exchange and interaction throughout the earth sciences - the surest path to new knowledge about subduction zones. 